\title{
Impact of MyDiabetesPlan, a Web-Based Patient Decision Aid on Decisional Conflict, Diabetes Distress, Quality of Life, and Chronic Illness Care in Patients With Diabetes: Cluster Randomized Controlled Trial
}

Catherine $\mathrm{Yu}^{1,2,3,4}$, BSc, MHSc, MD, FRCPC; Dorothy $\mathrm{Choi}^{1}$, BSc; Brigida A Bruno ${ }^{5}$, BSc, MD; Kevin E Thorpe ${ }^{3,6}$, MMath; Sharon E Straus ${ }^{2,4}$, HSBc, MSc, MD, FRCPC; Paul Cantarutti ${ }^{7}$, MD; Karen Chu ${ }^{8}$, MD; Paul Frydrych ${ }^{9}$, MD; Amy Hoang-Kim ${ }^{1}$, MSc, PhD; Noah Ivers ${ }^{10,11}$, MD, PhD; David Kaplan ${ }^{11,12}$, MSc, MD; Fok-Han Leung ${ }^{1}$, MD; John Maxted $^{13}$, MD; Jeremy Rezmovitz ${ }^{14}$, MD; Joanna Sale ${ }^{15}$, MSc, PhD; Sumeet Sodhi-Helou ${ }^{16}$, MPH, MD; Dawn Stacey ${ }^{17}$, BScN, MScN, PhD; Deanna Telner ${ }^{18}$, MD

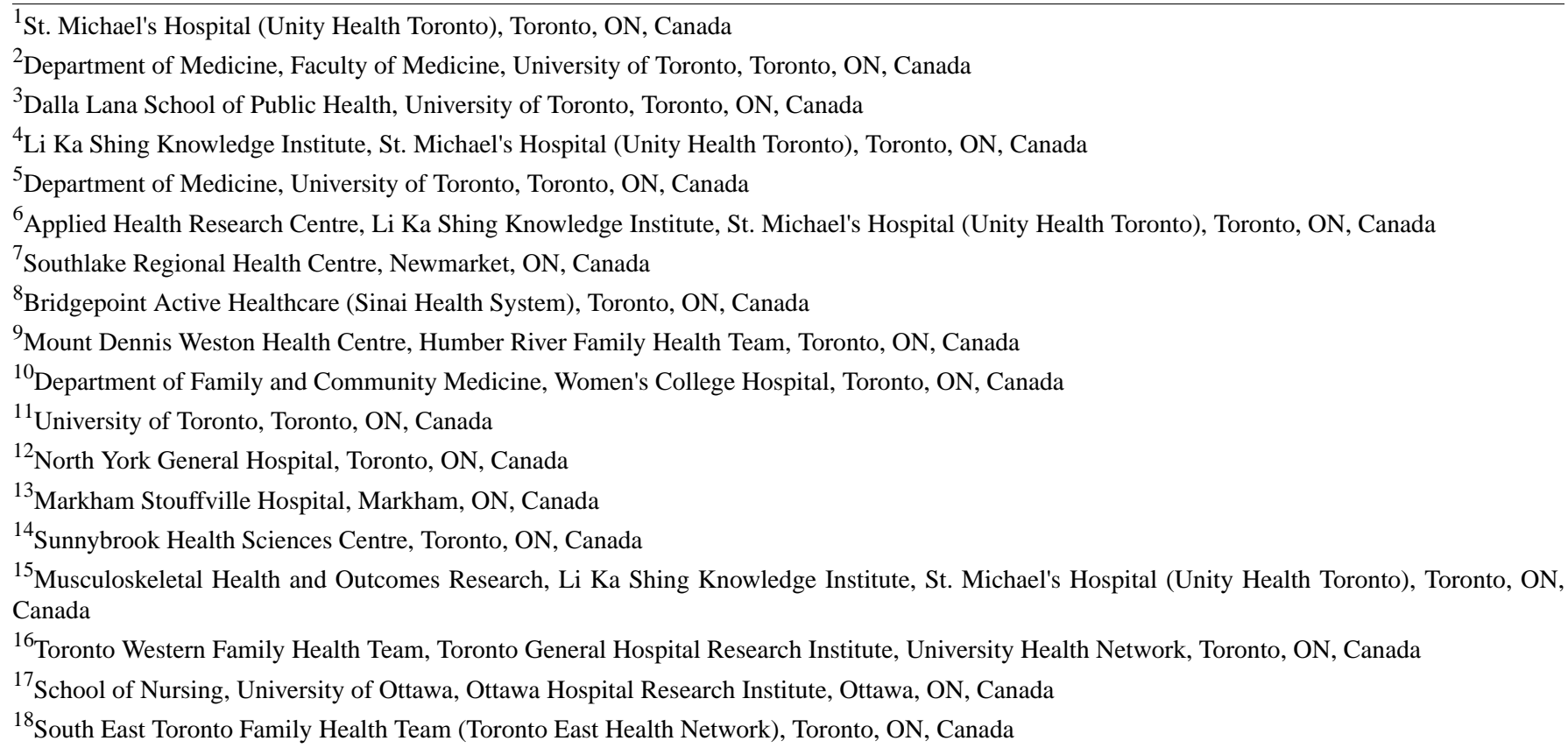

\section{Corresponding Author:}

Catherine Yu, BSc, MHSc, MD, FRCPC

St. Michael's Hospital (Unity Health Toronto)

30 Bond St

Toronto, ON

Canada

Phone: 14168646060

Email: catherine.yu@unityhealth.to

\section{Abstract}

Background: Person-centered care is critical for delivering high-quality diabetes care. Shared decision making (SDM) is central to person-centered care, and in diabetes care, it can improve decision quality, patient knowledge, and patient risk perception. Delivery of person-centered care can be facilitated with the use of patient decision aids (PtDAs). We developed MyDiabetesPlan, an interactive SDM and goal-setting PtDA designed to help individualize care priorities and support an interprofessional approach to SDM. 
Objective: This study aims to assess the impact of MyDiabetesPlan on decisional conflict, diabetes distress, health-related quality of life, and patient assessment of chronic illness care at the individual patient level.

Methods: A two-step, parallel, 10-site cluster randomized controlled trial (first step: provider-directed implementation only; second step: both provider- and patient-directed implementation 6 months later) was conducted. Participants were adults 18 years and older with diabetes and 2 other comorbidities at 10 family health teams (FHTs) in Southwestern Ontario. FHTs were randomly assigned to MyDiabetesPlan $(n=5)$ or control $(n=5)$ through a computer-generated algorithm. MyDiabetesPlan was integrated into intervention practices, and clinicians (first step) followed by patients (second step) were trained on its use. Control participants received static generic Diabetes Canada resources. Patients were not blinded. Participants completed validated questionnaires at baseline, 6 months, and 12 months. The primary outcome at the individual patient level was decisional conflict; secondary outcomes were diabetes distress, health-related quality of life, chronic illness care, and clinician intention to practice interprofessional SDM. Multilevel hierarchical regression models were used.

Results: At the end of the study, the intervention group ( 5 clusters, $n=111$ ) had a modest reduction in total decisional conflicts compared with the control group ( 5 clusters, $n=102 ;-3.5,95 \% \mathrm{CI}-7.4$ to 0.42$)$. Although there was no difference in diabetes distress or health-related quality of life, there was an increase in patient assessment of chronic illness care $(0.7,95 \%$ CI 0.4 to 1.0).

Conclusions: Use of goal-setting decision aids modestly improved decision quality and chronic illness care but not quality of life. Our findings may be due to a gap between goal setting and attainment, suggesting a role for optimizing patient engagement and behavioral support. The next steps include clarifying the mechanisms by which decision aids impact outcomes and revising MyDiabetesPlan and its delivery.

Trial Registration: ClinicalTrials.gov NCT02379078; https://clinicaltrials.gov/ct2/show/NCT02379078

(J Med Internet Res 2020;22(9):e16984) doi: 10.2196/16984

\section{KEYWORDS}

shared decision making; goals of care; decision aid; diabetes mellitus; decisional conflict; quality of life; patient assessment of chronic illness care; diabetes distress; randomized clinical trials

\section{Introduction}

Person-centered care, whereby health care providers are encouraged to partner with patients to co - design and deliver personalized care [1], is critical to delivering high-quality diabetes care [2]. Shared decision making (SDM) is central to person-centered care [3] and can be facilitated with the use of patient decision aids (PtDAs), such as Diabetes Medication Choice [4] or patient activation programs [5]. A meta-analysis of 16 studies using SDM in diabetes care found an association with improved decision quality, patient knowledge, and patient risk perception [6]. Decisional conflict is a measure of decision quality and reflection of the individual's uncertainty in choosing an option [7]. Decisions with low decisional conflict have been associated with less regret [8] and less emotional and psychological distress [9]. Thus, engagement of the person in the decision-making process to make a high-quality decision is an important step in delivering person-centered care.

Other markers of person-centered care in diabetes management include health-related quality of life [10], diabetes distress [11], and perception of chronic illness care [12]. Health-related quality of life reflects the combined impact of an individual's physical, psychological, and social well-being on health-related quality of life, and in patients living with diabetes, lower quality of life is associated with poorer clinical outcomes such as glycemic control [13]. Decisional conflict is a reflection of an individual's uncertainty in choosing an option, whereas diabetes distress refers to an individual's emotional state as a result of the burden of self-care tasks related to diabetes self-management and is associated with reduced self-care, reduced quality of life, and poor glycemic control [11,14]. Similarly, an individual's positive perception of chronic illness care is associated with improved self-management behaviors and glycemic control [12]. Thus, these outcomes reflect person-centered care.

\section{Decision Aids to Support Person-Centered Care}

Delivery of person-centered care and optimization of these outcomes can be facilitated with the use of PtDAs. A systematic review of 105 studies found that PtDAs improved decision quality and process and reduced decisional conflict but had no impact on quality of life [15]. For trials evaluating PtDAs for diabetes decisions, patients were more likely to change their medication. With the evolution of technology, PtDAs have expanded from static pamphlets, booklets, or videos to include interactive video- and computer-based programs; the latter enable individualized content tailored to the patient's characteristics and needs $[16,17]$.

Given the complexity of diabetes care and multiple competing priorities, decision aids that support goal setting are particularly relevant. To date, one randomized controlled trial (RCT) of a goal-setting and SDM aid (which offered individually tailored risk information and treatment options for multiple risk factors to help patients prioritize between clinical issues) in 344 patients with uncomplicated type 2 diabetes found no difference in patient empowerment for setting and achieving goals [18]. However, this intervention neither addressed patient-important priorities and preferences specifically nor used a provider-specific point-of-care tool at the time of consultation. 


\section{Objectives}

To address this gap, we developed MyDiabetesPlan and a multicomponent PtDA toolkit, which includes patient-directed, provider-directed, and point-of-care tools. MyDiabetesPlan is an interactive SDM and goal-setting PtDA designed to help individualize care priorities and support an interprofessional approach to SDM, in the context of complex guideline recommendations for patients with type 1 or type 2 diabetes and other comorbidities. The overall aim of this study was to assess the impact of MyDiabetesPlan on decisional conflict, diabetes distress, health-related quality of life, and patient assessment of chronic illness care in individual patients in primary care practice groups randomized to MyDiabetesPlan.

\section{Methods}

\section{Research Program Overview}

We previously reported on how the development and refinement of MyDiabetesPlan, an interprofessional shared decision-making (IPSDM) toolkit, following the principles of user-centered design [19,20]. In this paper, we describe our assessment of the effectiveness of MyDiabetesPlan through a two-step cluster RCT followed by individual interviews. We used the Consolidated Standards of Reporting Trials (CONSORT) checklist (CONSORT-eHealth [21] and CONSORT extension for cluster trials [22]) to report this paper (Multimedia Appendix $1)$.

\section{Study Design}

The study protocol and methods are described in previous studies $[19,23]$. We conducted a two-step, parallel, cluster RCT with a 1:1 allocation ratio. We selected a clustered design and randomized at the level of primary care practice groups to avoid contamination (eg, clinicians using an IPSDM approach with control patients). In brief, the first step was provider-directed (MyDiabetesPlan was delivered to physicians, nurses, dietitians, or pharmacists), whereas the second step (occurring 6 months later) was provider- and patient-directed (patients were asked to use MyDiabetesPlan by themselves before the appointment; this was then reviewed by the provider team). We chose a two-step approach because a prior feasibility study [20] identified that patients required clinician assistance for completing their initial MyDiabetesPlan. Outcome measures were administered at the first step (baseline), second step (6 months later), and follow-up (12 months later).

\section{Setting and Participants}

All primary care practice groups in Southern Ontario that had interprofessional staff (eg, nurse, dietitian, or pharmacist) and electronic medical records (EMRs, to identify patients with diabetes) were invited to participate via email, telephone, and in-person or virtual presentation to the executive or medical director; groups without interprofessional staff or EMRs were excluded. All primary care physicians in these group practices were invited to participate. A research coordinator identified patients with diabetes (type 1 or type 2) and 2 other comorbidities (heart disease, stroke, hypertension, cancer, chronic lung disease, arthritis, inflammatory bowel disorders, and urinary incontinence) from each consenting physician's practice using a combination of keywords, International Classification of Diseases and billing codes. Patients were excluded if they did not speak English, had documented cognitive deficits, were unable to provide informed consent, had limited life expectancy ( $<1$ year), or were not available for follow-up. Potentially eligible patients were identified via EMR query, and eligibility was further confirmed by chart review; from this group, participants were randomly selected and invited to participate and provided consent by telephone.

\section{Intervention}

MyDiabetesPlan was described previously [19]. It is a web-based PtDA in which patients populate their cardiometabolic and psychosocial profiles and general care priorities; MyDiabetesPlan then generates individualized diabetes-specific goals and strategies based on these inputs that the patients then select, resulting in an action plan. After randomization, at study onset, clinicians at intervention sites underwent a one-on-one 60-min tutorial in their clinic room by the research coordinator, with access to a one-page how-to guide and 2-min video. During subsequent clinical encounters, a member of the interprofessional team (nurse or dietitian) logged into MyDiabetesPlan and completed it with the patient; the physician subsequently reviewed the resultant action plan with the patient. At 6 months, patients at intervention sites were provided with a patient-directed how-to guide and video and directed to update MyDiabetesPlan according to their progress before the appointment. The research coordinator followed up with participants by email and telephone at study onset, followed by quarterly debriefing sessions, in both individual and group formats.

\section{Control}

Clinicians in the control sites received paper copies of the executive summary of the Diabetes Canada clinical practice guidelines [24] and a postcard outlining web-based clinical information resources. After 6 months, patients in the control sites received a Diabetes Canada patient education pamphlet [25] regarding diabetes self-management and a postcard outlining web-based additional patient resources.

\section{Outcome Measures}

The primary outcome was decisional conflict [26]; secondary outcomes were diabetes distress [27], health-related quality of life [28], chronic illness care [29], and intention to engage in IPSDM [30] (Table 1). Decisional conflict was measured using the Decisional Conflict Scale (DCS), which can predict individuals' intentions and subsequent behavior. It has a test-retest coefficient of 0.81 and internal consistency coefficients ranging from 0.78 to 0.92 [7]. These outcomes were assessed at the individual participant level, at baseline, and at 6 months and 12 months (after an appointment) through a web-based survey or by mail. 
Table 1. Outcome measures and validated scales.

\begin{tabular}{lll}
\hline Outcome & Scale & Description and psychometric properties \\
\hline Patient outcomes & $\begin{array}{l}\text { Decisional conflict } \\
\mathrm{DCS}^{\mathrm{a}}(16-\mathrm{item}, 5 \text { subscales; } \\
\left.\mathrm{O}^{\prime} \mathrm{Connor}, 1995\right) \text { [7] }\end{array}$ & $\begin{array}{l}\text { This scale consists of } 16 \text { items with } 5 \text { response categories }(0=\text { strongly agree, } \\
\text { 4=strongly disagree), where higher scores indicate greater decisional conflict. The } \\
\text { scale includes subscales for uncertainty, informed, values clarity, support, and effec- } \\
\text { tive decision. Test-retest correlation and Cronbach alpha exceed .78. It correlated } \\
\text { with related constructs of knowledge, regret, and discontinuance and had excellent } \\
\text { predictive validity. A clinically significant effect size is } 0.30 \text { to } 0.40 ; \text { scores lower } \\
\text { than } 25 \text { are associated with implementing decision; scores exceeding } 37.5 \text { are asso- } \\
\text { ciated with decision delay or feeling unsure about implementation. The primary } \\
\text { outcome decisional conflict has been demonstrated to be responsive to change over } \\
\text { time and thus will yield meaningful results when measured at baseline and throughout } \\
\text { the study intervention. }\end{array}$
\end{tabular}

Diabetes distress $\quad$ DDS $^{\mathrm{b}}$ (Polonsky et al, 2005) [27] The DDS is a 17-item instrument that assesses emotional distress and functioning specific to living with diabetes. Responses are scored on a 6-point Likert-type scale from $1=$ no problem to $6=$ serious problem. Scores can range from 17 to 102 , with higher scores indicating poorer diabetes-related quality of life and lower scores indicating better diabetes-related quality of life. This instrument has been found to have high internal reliability with a Cronbach alpha of .93 , good convergent validity with the $\operatorname{CESD}^{\mathrm{c}}(r=0.56)$ and self-care behaviors including lower adherence to eating recommendations $(r=0.30)$ and lower levels of physical activity $(r=0.20)$.

Health-related quali- $\quad \mathrm{SF}^{\mathrm{d}}-12$ (Ware, 1996) [31] ty of life

The SF-12 is a 12 -item version of the SF-36. The SF-12 is a widely used and validated generic measure of health-related quality of life. It is a multidimensional measure of perceived health, assessing physical functioning, physical role, bodily pain, general health, vitality, social functioning, emotional role, and mental health. Scores ranges from 0 to 100 , with higher scores reflecting better health. Its validity was demonstrated in studies of patients with various chronic conditions [32,33].

Chronic illness care PACIC $^{\mathrm{e}}$ Scale (Glasgow et al, 2005) [29]

The PACIC Scale assesses the degree to which care is congruent with the Chronic Care Model from the perspective of the patient. Specifically, it was designed to measure patient activation, goal setting, problem solving/contextual counseling, delivery system design/decision support, and follow-up/coordination. The PACIC Scale has been used to evaluate a variety of chronic health conditions, including type 2 diabetes $[29,34,35]$. It has moderate test-retest reliability $(r=0.58$ during the course of 3 months) and correlates moderately with measures of primary care and patient activation $(r=0.32-0.60$, median $=0.50, P<.001)$.

Clinician outcome

Intention to engage $\quad \mathrm{CPD}^{\mathrm{g}}$ Reaction Questionnaire in $\operatorname{IPSDM}^{\mathrm{f}} \quad$ (Legare et al, 2014) [36]

This 11-item questionnaire is based on the Theory of Planned Behavior, encompassing instrumental attitude, affective attitude, subjective norm, and perceived behavioral control. It has a reliability that ranges from 0.67 to 0.93 [37]

${ }^{\mathrm{a} D C S}$ : Decisional Conflict Scale.

${ }^{b}$ DDS: Diabetes Distress Scale.

${ }^{\mathrm{c}}$ CESDS: Center for Epidemiological Studies Depression Scale.

${ }^{\mathrm{d}} \mathrm{SF}$ : Short Form.

${ }^{\mathrm{e}}$ PACIC: Patient Assessment of Chronic Illness Care.

${ }^{\mathrm{f}}$ IPSDM: interprofessional shared decision-making.

${ }^{\mathrm{g}}$ CPD: Continuing Professional Development.

\section{Sample Size Calculation}

With at least 40 patients per physician, $50 \%$ patient participation rate, and an anticipated patient attrition rate of $25 \%$ [38], we estimated that approximately 15 patients per practice would be able to participate. On the basis of a previous study using the DCS [7], we selected a standardized effect size of 0.4 with an SD of $0.6, \alpha$ of .05 , and $\beta$ of .10. Previous data have shown that $\rho$ (intraclass coefficient) for decisional conflict for patients living with diabetes clustered within primary care physicians is 0.013 [39]. Therefore, accounting for clustering, 56 patients per intervention/control group, or 4 sites per intervention/control group would be required.

\section{Randomization}

Practices were simultaneously randomized and allocated by a biostatistician to either intervention or control using computer-generated randomization in a 1:1 ratio. Each practice was given a code, and the biostatistician was blinded to the allocation status. After assignment, investigators, research coordinators, and trial participants were no longer blinded to group allocation owing to the nature of the intervention. The list of all eligible patients from each cluster was randomly 
ordered; patients were recruited from this list until the target sample size was met.

\section{Data Collection}

The practice and sociodemographic characteristics of clinicians and patients were obtained at baseline. Outcome data were collected using participant questionnaires [23] distributed through web or by mail according to patient preference for pragmatic reasons at baseline, 6 months, and 12 months.

\section{Analysis}

A modified intent-to-treat analysis was conducted. For the primary and secondary outcomes, a linear mixed effect model was used to analyze the total score for each scale where site was the random effect with adjustment for baseline value. To account for missing data, we conducted a fully adjusted mixed effect model using repeated measurements [40-42]. The baseline variables we adjusted for were baseline DCS score, age, sex, ethnicity, educational attainment, employment, and living arrangements as well as a history of cancer and heart, musculoskeletal, respiratory, mental health, kidney, eye, and nerve disease.

The impact of sociodemographic variables on these outcomes (decisional conflict, diabetes distress, health-related quality of life, and chronic illness care) was assessed. Specifically, we fit a main effects model that adjusted for age, sex, ethnicity, education, employment status, and living arrangements as well as a fully adjusted model that included all interactions between treatment and the preceding variables. As these subgroup analyses were explorative, these were performed on the complete case data because the use of repeated measure data would necessitate the need for interactions with time as well. $P$ values for the treatment effect in the baseline adjusted models used Satterthwaite approximation for the denominator degrees of freedom, whereas the tests of interactions (subgroup effects) used likelihood ratio tests from a full maximum likelihood estimation [43]. Irrespective of the test result on subgroups, the treatment effects were then shown by subgroup, estimated from the second model specified above, along with $95 \% \mathrm{CI}$ and a $P$ value that tested each interaction in this fully adjusted model. Descriptive statistics were used to describe the intervention effect by MyDiabetesPlan use. Analysis of variance was used to assess differences in the clinician's intention to practice
IPSDM scores between the intervention and control groups at baseline, 6 months, and 12 months. Analysis was performed in $\mathrm{R}$ version 3.5.2 [44], and the packages lme4 (version 1.1-21) and lmerTest (version 3.1-0) [43] were used to fit and report the mixed effect models.

\section{Research Ethics}

The study was approved by the Research Ethics Boards of Bridgepoint Health (15-009-BP), Markham Stouffville Hospital (Canadian Institutes of Health Research [CIHR] protocol, v1, January 2013), Michael Garron Hospital (609-1410-Mis-245), North York General Hospital (13-0265), Southlake Regional Health Centre (0055-1314), St. Michael's Hospital (13-014; includes Humber River Regional Hospital), Sunnybrook Health Sciences Health Centre (345-2013), University Health Network (16-6044), and Women's College Hospital (2013-2058, 2014-0043-B).

\section{Funding}

The study was funded by the CIHR Knowledge to Action Operating Grant (Funding reference number KAL 290086), which had no role in the design, collection, management, analysis or interpretation of data, or in the writing or publication of the manuscript. SS is supported by a Tier 1 Canada Research Chair. NI was supported by New Investigator Awards from CIHR and from the Department of Family and Community Medicine, University of Toronto.

\section{Results}

\section{Setting and Participants}

A total of 10 primary care practice groups were recruited from December 2014 to November 2015; patients were recruited from December 2015 to September 2016, followed by October 2016 to September 2017. Recruitment metrics and the CONSORT flow diagram are shown in Figure 1. The practice and sociodemographic characteristics of clinicians and patients are shown in Table 2. In the intervention group, 50.0\% (51/102) and $46 \%$ (33/72) of participants completed the questionnaire via web-based platform for time points 1 and 3, respectively. In the control group, $47.7 \%$ (53/111) and 51\% (40/79) of participants completed the questionnaire via web-based platform for time points 1 and 3, respectively (Multimedia Appendix 1). 
Figure 1. CONSORT (Consolidated Standards of Reporting Trials) flow diagram. DM: diabetes mellitus; FHT: family health team.

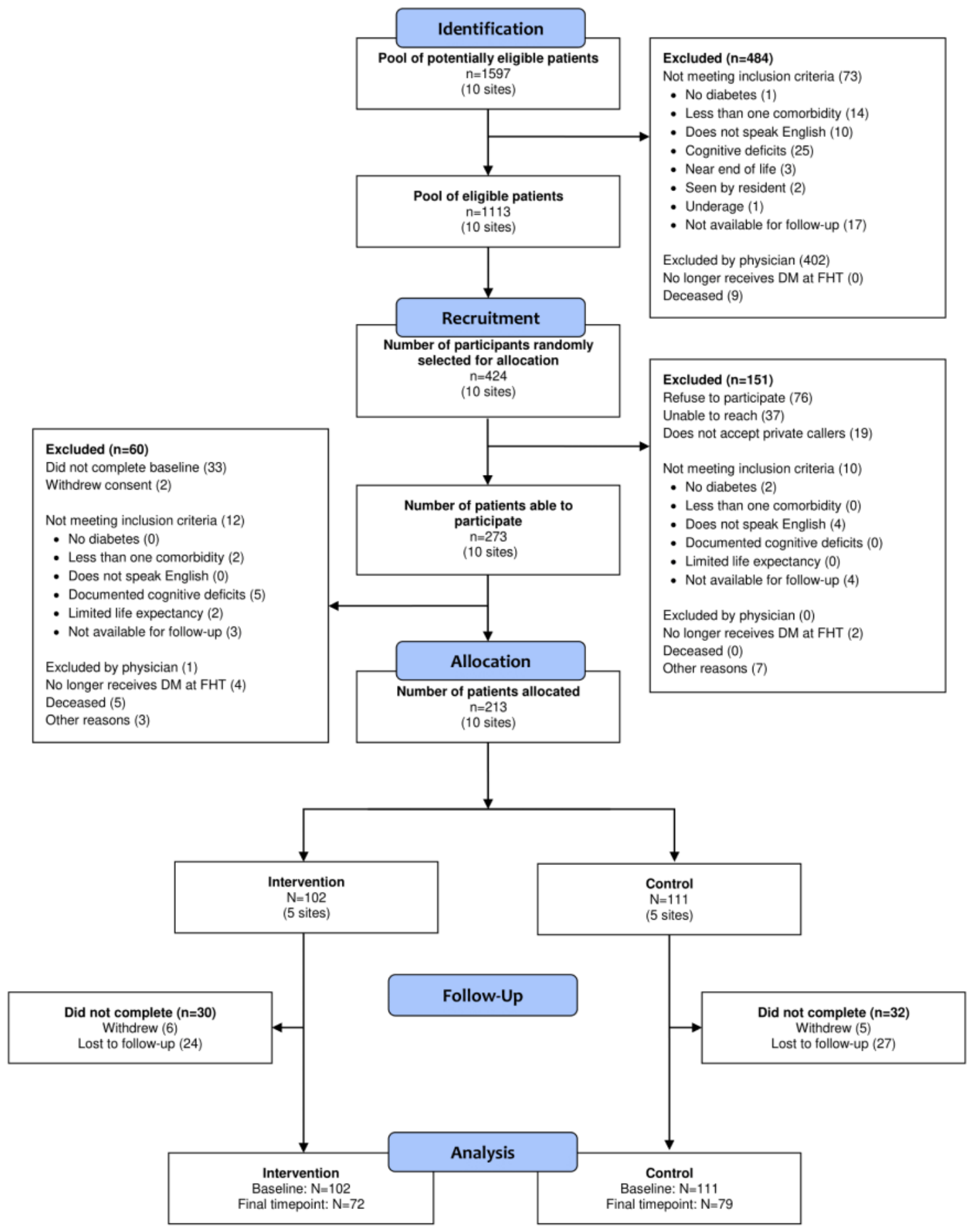


Table 2. Clinician and patient characteristics.

\begin{tabular}{|c|c|c|}
\hline Characteristics & Control, n (\%) & Intervention, $\mathrm{n}(\%)$ \\
\hline Clinician & $24(100)$ & $29(100)$ \\
\hline \multicolumn{3}{|l|}{ Sex at birth } \\
\hline Female & $11(46)$ & $21(72)$ \\
\hline Male & $10(42)$ & $7(25)$ \\
\hline Prefer not to answer & $3(12)$ & $1(3)$ \\
\hline \multicolumn{3}{|c|}{ Duration in practice (years) } \\
\hline $2-5$ & $7(29)$ & $5(17)$ \\
\hline $6-10$ & $5(21)$ & $8(28)$ \\
\hline$\geq 11$ & $12(50)$ & $16(55)$ \\
\hline \multicolumn{3}{|c|}{ Number of patients with diabetes seen per week } \\
\hline$<10$ & $12(50)$ & $17(59)$ \\
\hline$\geq 10$ & $12(50)$ & $10(34)$ \\
\hline Unsure & $0(0)$ & $2(7)$ \\
\hline \multicolumn{3}{|l|}{ Type of health team } \\
\hline Community & $20(83)$ & $5(17)$ \\
\hline Academic & $4(17)$ & $24(83)$ \\
\hline Patients & $111(100)$ & $102(100)$ \\
\hline \multicolumn{3}{|l|}{ Age (years) } \\
\hline $18-44$ & $7(6.3)$ & $2(2.0)$ \\
\hline $45-54$ & $9(8.1)$ & $11(11.0)$ \\
\hline $55-64$ & $28(25.2)$ & $20(20.0)$ \\
\hline $65-74$ & $38(34.2)$ & $47(47.0)$ \\
\hline $75-84$ & 24 (21.6) & $16(16.0)$ \\
\hline$\geq 85$ & $5(4.5)$ & $4(4.0)$ \\
\hline \multicolumn{3}{|l|}{ Sex at birth } \\
\hline Female & $46(41.4)$ & $56(54.9)$ \\
\hline Male & $65(58.6)$ & $46(45.1)$ \\
\hline \multicolumn{3}{|l|}{ Language } \\
\hline English & $103(92.8)$ & $81(81.0)$ \\
\hline Other & $8(7.2)$ & $19(19.0)$ \\
\hline \multicolumn{3}{|l|}{ Ethnicity } \\
\hline White & 75 (67.6) & $62(63.3)$ \\
\hline Black & $8(7.2)$ & $5(5.1)$ \\
\hline Asian & $8(7.2)$ & 19 (18.6) \\
\hline Indigenous & $3(2.7)$ & $4(4.1)$ \\
\hline Latin American & $2(1.8)$ & $1(1.0)$ \\
\hline Other & $15(13.5)$ & $7(7.1)$ \\
\hline \multicolumn{3}{|l|}{ Education } \\
\hline Bachelor's & $17(16.0)$ & $23(23.2)$ \\
\hline Below bachelor & $5(4.7)$ & $3(3.0)$ \\
\hline College & $26(24.5)$ & $30(30.3)$ \\
\hline High school & $31(29.2)$ & $19(19.2)$ \\
\hline
\end{tabular}




\begin{tabular}{|c|c|c|}
\hline Characteristics & Control, n (\%) & Intervention, $\mathrm{n}(\%)$ \\
\hline Postgraduation & $12(11.3)$ & $13(13.1)$ \\
\hline Below high school & $15(1.2)$ & $11(11.1)$ \\
\hline \multicolumn{3}{|l|}{ Employment } \\
\hline Retired & $63(58.3)$ & $54(55.1)$ \\
\hline Full time with employee health benefits & $15(13.9)$ & $22(22.4)$ \\
\hline Full time/part time without employee health benefits & $8(7.4)$ & $8(8.2)$ \\
\hline Government assistance/disability & $6(5.6)$ & $3(3.1)$ \\
\hline Unemployed & $5(4.6)$ & $2(2.0)$ \\
\hline Stay-at-home parent, student, volunteer & $5(4.6)$ & $2(2.0)$ \\
\hline Other & $4(3.7)$ & $7(7.1)$ \\
\hline Prefer not to answer & $2(1.9)$ & $0(0.0)$ \\
\hline \multicolumn{3}{|l|}{ Income, Can \$ (US \$) } \\
\hline$<10,000(7603)$ & $9(8.7)$ & $6(7.6)$ \\
\hline $10,000-19,000(7603-14,446)$ & $18(17.5)$ & $6(7.6)$ \\
\hline $20,000-29,000(15,206-22,048)$ & $8(7.8)$ & $5(6.3)$ \\
\hline $30,000-39,000(22,809-29,651)$ & $13(12.6)$ & $7(8.9)$ \\
\hline $40,000-49,000(22,543-37,254)$ & $10(9.7)$ & $7(8.9)$ \\
\hline $50,000-59,000(38,015-44,857)$ & $8(7.8)$ & $5(6.3)$ \\
\hline $60,000-69,000(45,617-52,460)$ & $3(2.9)$ & $6(7.6)$ \\
\hline $70,000-79,000(53,220-60,063)$ & $6(5.8)$ & $6(7.6)$ \\
\hline $80,000-89,000(60,823-67,666)$ & $2(1.9)$ & $6(7.6)$ \\
\hline $90,000-99,000(68,426-75,269)$ & $8(7.8)$ & $6(7.6)$ \\
\hline $100,000-149,000(76,029-113,283)$ & $7(6.8)$ & $8(10.1)$ \\
\hline$\geq 150,000(114,044)$ & $11(10.7)$ & $11(13.9)$ \\
\hline \multicolumn{3}{|l|}{ Living arrangements } \\
\hline Alone & $30(27.3)$ & $26(25.7)$ \\
\hline With family members & $24(21.8)$ & $28(27.7)$ \\
\hline With partner/spouse & $46(41.8)$ & 38 (37.6) \\
\hline With roommates & $2(1.8)$ & $3(3.0)$ \\
\hline Other & $8(7.3)$ & $6(5.9)$ \\
\hline
\end{tabular}

\section{Attrition Analysis}

A total of 62 patients withdrew or were lost to follow-up. Of these patients, we had demographic data on 34 patients (control, $\mathrm{n}=10$; intervention, $\mathrm{n}=24$; Multimedia Appendix 1). There were proportionately more non-English-speaking patients (9/34, $26 \%$ ) with high school education $(11 / 34,32 \%)$ who withdrew, compared with those who remained in the study.

\section{Primary Outcome: Decisional Conflict}

Total decisional conflict was modestly reduced in the intervention group at 12 months compared with the control group ( -3.5 of a total score of $100,95 \% \mathrm{CI}-7.4$ to $0.4, P=.08$; Table 3). At 12 months, the Uninformed subscale was reduced in the intervention group $(-3.9,95 \% \mathrm{CI}-8.8$ to $-1.02, P=.11)$. Similarly, at 12 months, the Unclear Values subscale was reduced in the intervention group $(-3.6,95 \% \mathrm{CI}-9.6$ to 2.28 , $P=$.21).

\section{Secondary Outcomes}

\section{Patient Chronic Care, Diabetes Distress, and Quality of Life}

Patient assessment of chronic illness care increased in the intervention group compared with the control group ( 0.7 of a total score of $5,95 \%$ CI 0.4 to $1.0, P<.001)$. There was a small difference in diabetes distress $(-0.2,95 \% \mathrm{CI}-0.4$ to 0.05 , $P=.12)$ and quality of life $(1.2,95 \% \mathrm{CI}-3.2$ to $5.5, P=.57$; Table $3)$. 
Table 3. Scores at baseline, 6 and 12 months, and treatment effect at 6 and 12 months for decisional conflict, patient assessment of chronic illness care, diabetes distress, and quality of life.

\begin{tabular}{|c|c|c|c|c|c|c|c|c|c|c|}
\hline \multirow[t]{3}{*}{ Outcome measures } & \multicolumn{6}{|c|}{ Score, mean (SD) } & \multicolumn{4}{|c|}{ Treatment effect } \\
\hline & \multicolumn{3}{|l|}{ Control } & \multicolumn{3}{|l|}{ Intervention } & \multicolumn{2}{|l|}{6 months } & \multicolumn{2}{|l|}{12 months } \\
\hline & Baseline & 6 months & $\begin{array}{l}12 \\
\text { months }\end{array}$ & Baseline & 6 months & 12 months & $\begin{array}{l}\text { Mean, 95\% } \\
\text { CI }\end{array}$ & $P$ value & $\begin{array}{l}\text { Mean, } \\
95 \% \text { CI }\end{array}$ & $P$ value \\
\hline $\begin{array}{l}\mathrm{DCS}^{\mathrm{a}} \text { (out of } 100 \text {; } \\
\text { higher score repre- } \\
\text { sents more deci- } \\
\text { sional conflict) }\end{array}$ & $\begin{array}{l}23.56 \\
(15.00)\end{array}$ & $\begin{array}{l}21.10 \\
(12.79)\end{array}$ & $\begin{array}{l}19.58 \\
(9.11)\end{array}$ & $\begin{array}{l}25.53 \\
(14.73)\end{array}$ & $\begin{array}{l}21.97 \\
(14.87)\end{array}$ & $\begin{array}{l}17.35 \\
(11.21)\end{array}$ & $\begin{array}{l}-1.82,-6.02 \\
\text { to } 2.38\end{array}$ & .38 & $\begin{array}{l}-3.49 \\
-7.4 \text { to } \\
-0.42\end{array}$ & .08 \\
\hline PACIC $^{\mathrm{b}}$ (out of 5) & $3.16(0.95)$ & $\begin{array}{l}3.41 \\
(1.05)\end{array}$ & $\begin{array}{l}3.22 \\
(1.08)\end{array}$ & $2.82(1.10)$ & $3.16(1.10)$ & $3.68(0.99)$ & $\begin{array}{l}0.15,-0.19 \\
\text { to } 0.50\end{array}$ & .35 & $\begin{array}{l}0.71,0.38 \\
\text { to } 1.04\end{array}$ & $<.001$ \\
\hline $\operatorname{DDS}^{\mathrm{c}}$ (out of 6) & $1.93(0.83)$ & $\begin{array}{l}1.88 \\
(0.78)\end{array}$ & $\begin{array}{l}1.90 \\
(0.75)\end{array}$ & $2.08(1.02)$ & $1.92(1.09)$ & $1.86(0.87)$ & $\begin{array}{l}-0.08,-0.34 \\
\text { to } 0.18\end{array}$ & .53 & $\begin{array}{l}-0.18 \\
-0.42 \text { to } \\
0.05\end{array}$ & .12 \\
\hline $\begin{array}{l}\text { Quality of Life } \\
\left(\mathrm{SF}^{\mathrm{d}}-12 \text {; out of }\right. \\
100)\end{array}$ & $\begin{array}{l}89.69 \\
(12.48)\end{array}$ & $\begin{array}{l}87.77 \\
(12.87)\end{array}$ & $\begin{array}{l}86.99 \\
(10.69)\end{array}$ & $\begin{array}{l}87.35 \\
(14.25)\end{array}$ & $\begin{array}{l}88.88 \\
(13.56)\end{array}$ & $\begin{array}{l}87.94 \\
(12.87)\end{array}$ & $\begin{array}{l}3.47,-1.05 \\
\text { to } 7.98\end{array}$ & .12 & $\begin{array}{l}1.18 \\
-3.18 \text { to } \\
5.54\end{array}$ & .57 \\
\hline
\end{tabular}

${ }^{\mathrm{a} D C S}$ : Decisional Conflict Scale.

${ }^{b}$ PACIC: Patient Assessment of Chronic Illness Care.

${ }^{\mathrm{c}}$ DDS: Diabetes Distress Scale.

${ }^{\mathrm{d}}$ SF: Short Form.

\section{Intervention Effect of MyDiabetesPlan}

A total of 52 patients completed (eg, generated a complete plan) MyDiabetesPlan two or more times during the study period.
The greatest reduction in decisional conflict occurred in patients who completed MyDiabetesPlan more than 2 times, whereas the smallest reduction in decisional conflict occurred in patients who completed it 2 times (Table 4).

Table 4. Change in decisional conflict over 12 months in the intervention group using MyDiabetesPlan by number of completed plans.

\begin{tabular}{lllll}
\hline Completed plans, $n$ & Participants, $n(\mathrm{~N}=68)$ & \multicolumn{2}{l}{ Decisional conflict score, mean (SD) } \\
& & 0 months & 12 months & Change in score \\
\hline$<1$ & 6 & $23.4(22.7)$ & $14.9(11.8)$ & $-8.5(22.4)$ \\
1 & 20 & $23.2(12.9)$ & $13.9(11.6)$ & $-9.3(10.6)$ \\
2 & 29 & $26.9(10.9)$ & $21.2(11.5)$ & $-5.7(12.5)$ \\
$>2$ & 13 & $32.1(22.5)$ & $19.8(14.6)$ & $-12.3(20.9)$ \\
\hline
\end{tabular}

\section{Subgroup Analyses}

For decisional conflict, we found weak evidence for any interaction $(P=.07)$ that appeared to be driven by age $>65$ years $(P=.01$; Multimedia Appendix 1). We found stronger evidence when we examined the "uninformed" subscale $(P=.03)$, driven by age $>65$ years $(P=.003)$, and income $>$ Can $\$ 50,000$ (US $\$ 379,000 ; P=.04)$. Similarly, for diabetes distress, there was weak evidence for interaction $(P=.14)$ driven by age $>65$ years $(P=.01)$ and unemployment status $(P=.03)$. There was weak evidence for interactions for PACIC $(P=.01$; lives alone: $P=.11)$. There was little evidence of discernible interactions for the Short Form-12.

\section{Intention to Engage in IPSDM}

There was little evidence of differences between the 2 groups of clinicians in intention to practice SDM (Multimedia Appendix $1)$.

\section{Harms}

There were no harms associated with participation in this study.

\section{Discussion}

\section{Principal Findings}

We found that MyDiabetesPlan, an interprofessional goal-setting decision aid for people living with diabetes, resulted in a modest reduction in decisional conflict (specifically the uninformed subscale) and increased patient assessment of chronic illness care but had no impact on diabetes distress or health-related quality of life. MyDiabetesPlan reduced decisional conflict and diabetes distress most prominently in participants older than 65 years. There was no impact of MyDiabetesPlan use on clinicians' intention to practice SDM.

Our finding regarding the impact of MyDiabetesPlan on decisional conflict is generally consistent with the literature, although our results did not meet statistical significance. A 2017 
systematic review found that decision aids reduced decisional conflict related to uncertainty caused by unclear values $(-8.81 / 100 ; 95 \%$ CI -11.99 to $-5.63 ; 23$ studies; $n=5068$; high-quality evidence) and feeling uninformed (-9.28/100; $95 \%$ $\mathrm{CI}-12.20$ to $-6.36 ; 27$ studies; $\mathrm{n}=5707$; high-quality evidence) [45]. In our study, we found smaller reductions: a 3.5-point reduction in the total scale, a 3.9-point reduction in the uninformed subscale, and a 3.7-point reduction in the unclear values subscale. This discrepancy may be due to the goal-setting nature of MyDiabetesPlan: rather than offering risks and benefits of a single discrete decision, it offered risks and benefits of multiple potential strategies. Thus, answering a question in this context, such as "I am clear about which benefits matter most to me" may be more challenging.

\section{Comparison With Previous Work}

Consistent with a previous review [45], we also found no impact of MyDiabetesPlan on general or condition-specific health-related quality of life such as diabetes distress (though there was a signal for an effect in participants older than 65 years). Authors have postulated that this may be owing to the fact that decision aids are often used in situations where the options have no clear health outcome advantage [45]. A subanalysis of this review identified 11 studies involving 2684 patients that examined the impact of PtDA on health-related quality of life [46]. Of the 11 trials, 6 trials neither reported difference in health-related quality of life between PtDA and control nor over time. This confirmed the lack of impact, suggesting that health-related quality of life may be an uninformative end point unless a specific hypothesis for its impact can be made [46]. Another potential reason for this is that the outcome is too distant from the act of using MyDiabetesPlan: patients may select a goal (such as increasing physical activity) but may not enact the goal (ie, actually increasing their physical activity), and thus may not experience any change in health-related quality of life. Although MyDiabetesPlan may have reduced decisional conflict and increased patient activation and thus increased goal setting, there may be a gap between goal setting and goal attainment; bridging this gap with additional behavioral supports to optimize goal attainment may then result in improvements in health-related quality of life.

Our finding that MyDiabetesPlan reduced decisional conflict and diabetes distress, particularly in participants older than 65 years, is consistent with the literature [47]. This systematic review of 22 studies examining the impact of PtDa in adults aged 65 years and older found that people exposed to a decision aid had greater knowledge (5 studies; mean difference 6.5, 95\% CI 0.76 to 12.25 ) and reduced decisional conflict (11 studies; mean difference -3.17 out of $100,95 \%$ CI -4.44 to 1.90 ). These findings are reassuring, particularly in light of concerns of social inequities and the digital health divide [48], and provide support that a digital health innovation such as MyDiabetesPlan is appropriate for a complex older population with multiple comorbidities.
The strengths of this study include rigorous adherence to RCT methodology (including central randomization, similar intervention and control groups at baseline, appropriate length of follow-up, use of validated scales, intention-to-treat analysis), its finding of reducing decisional conflict and improving chronic care delivery, especially in those older than 65 years, and its generalizability. We designed this study to assess the feasibility of implementing MyDiabetesPlan in interprofessional primary care settings; as such, it is primarily a pragmatic trial along the explanatory-pragmatic continuum [49]. Thus, our study results mainly reflect what would happen if MyDiabetesPlan would be implemented in the usual clinical practice of interprofessional primary care.

\section{Limitations}

Study limitations include the lack of blinding of participants (patients and clinicians) owing to the nature of the intervention, use of both paper- and web-based data collection methods, attrition rate of $29 \%$, and less-than-anticipated MyDiabetesPlan use, resulting in potential bias, and its lack of clinical outcome measures. Although different data collection methods may introduce respondent bias, recent literature has shown that response rates do not differ between paper- and web-based respondents [50] and that there was no difference in socioeconomic characteristics between paper- and web-based respondents [51]. Our attrition rate and reduced MyDiabetesPlan use were amplified by our complex study population, many of whom either withdrew owing to competing health concerns or were lost to follow-up, presumably for similar reasons. Challenges to conducting research in this population are well documented, and solutions for future studies include providing transportation compensation, conducting home visits, and encouraging greater engagement of family members [52]. Although we did not assess clinical outcome measures, we assessed proximal patient-reported outcomes appropriate for a decision-aid intervention, outcomes that have typically been underused in the literature [53], and outcomes that have been associated with clinical outcomes such as $A_{1 c}$ [12-14]. Assessment of researcher-selected clinical outcomes such as $A_{1 c}$ in a trial where patients are encouraged to select their own personalized goals is incongruent with the principles of person-centered outcomes research [54]. Future studies may consider the use of goal attainment scaling (which has some demonstrated validity evidence in the geriatric care setting) [55] or composite clinical outcomes, though this is not without its limitations [56].

\section{Conclusions}

MyDiabetesPlan modestly reduced decisional conflict and increased patient assessment of chronic illness care but had no impact on diabetes distress or health-related quality of life. The next steps in this research program are to engage with knowledge users (patients and their caregivers, clinicians, managers, and policy makers) to discuss the implications of these findings, modify MyDiabetesPlan and its mode of delivery, and consideration of clinical, organizational, and health care system contexts to plan scale-up to an implementation trial. 


\section{Acknowledgments}

All authors are members of the MyDiabetesPlan team. The authors thank our knowledge users Eva Butler, Jan Hux, Ted Daisley, Heather Whetstone, Pauline Wijeyesekera, and Art Scrannage for their invaluable insights, perspective, and time. We thank John Loach, Calvin Ke, Imran Somji, Joyce Hui, and Sasha Jovicic for assistance and input into MyDiabetesPlan design. We thank Sue Hall, Marc Settino, Rabiya Siddiqui from University of Toronto Practice-Based Research Network (UTOPIAN), Alanna Rigobon, Celia Cassiani, Lakmini Pinnaduwage, and Catherine Spagnuolo for assistance with site coordination. We thank all our patients, clinicians, and site administrators at our participating sites for their support and time: Bridgepoint Family Health Team (FHT), Health for All FHT, Humber River FHT, North York FHT, South East Toronto FHT, Southlake Regional Health Centre FHT, St. Michael's Hospital FHT, Sunnybrook Academic FHT, Toronto Western Hospital FHT, and Women's College Hospital FHT.

\section{Authors' Contributions}

CY conceived and designed the study and drafted the manuscript. DC and BB conducted data cleaning and drafted portions of the manuscript. KT assisted with study design, conducted statistical analyses, and contributed to manuscript development. SS assisted with study design and revised the manuscript critically for intellectual content.

PC, KC, PF, NI, AH, DK, FL, JM, JR, SS, and DT participated in the design of the study, site coordination, and revised the manuscript critically for intellectual content. JS and DS participated in the design of the study and revised the manuscript critically for intellectual content. All authors have read and approved the final manuscript.

Site leads for this were as follows: Paul Cantarutti, Southlake Regional Health Centre, Newmarket, Canada; Karen Chu, Bridgepoint Active Healthcare, Toronto, Canada; Paul Frydrych, Mount Dennis Weston Health Centre, Toronto, Canada; Noah Ivers, Family Practice Health Centre, Women's College Hospital \& University of Toronto, Toronto, Canada; David Kaplan, North York Family Health Team, Toronto, Canada; Fok-Han Leung, St. Michael's Hospital, Toronto, Canada; John Maxted, Markham Stouffville Hospital, Markham, Canada; Jeremy Rezmovitz, Sunnybrook Health Sciences Centre, Toronto, Canada; Sumeet Sodhi, Toronto Western Family Health Team, University Health Network, Toronto, Canada; Deanna Telner, South East Toronto Family Health Team, Toronto, Canada. The site coordinator for this study was as follows: Amy Hoang-Kim, St. Michael's Hospital, Toronto, Canada. The content experts were as follows: Joanna Sale, Musculoskeletal Health and Outcomes Research - Li Ka Shing Knowledge Institute of St. Michael's Hospital, Toronto, Canada; Dawn Stacey RN, PhD, School of Nursing, University of Ottawa, Senior Scientist, Ottawa Hospital Research Institute, Ottawa, Canada.

\section{Conflicts of Interest}

None declared.

\section{Multimedia Appendix 1}

Supplemental file including CONSORT (Consolidated Standards of Reporting Trials) checklists (cluster, eHealth) and supplemental Tables 1-4.

[PDF File (Adobe PDF File), 708 KB-Multimedia Appendix 1]

\section{References}

1. Santana MJ, Manalili K, Jolley RJ, Zelinsky S, Quan H, Lu M. How to practice person-centred care: a conceptual framework. Health Expect 2018 Apr;21(2):429-440 [FREE Full text] [doi: 10.1111/hex.12640] [Medline: 29151269]

2. Williams JS, Walker RJ, Smalls BL, Hill R, Egede LE. Patient-centered care, glycemic control, diabetes self-care, and quality of life in adults with type 2 diabetes. Diabetes Technol Ther 2016 Oct;18(10):644-649 [FREE Full text] [doi: 10.1089/dia.2016.0079] [Medline: 27541872]

3. Scholl I, Zill JM, Härter M, Dirmaier J. An integrative model of patient-centeredness - a systematic review and concept analysis. PLoS One 2014;9(9):e107828 [FREE Full text] [doi: 10.1371/journal.pone.0107828] [Medline: 25229640]

4. Mullan RJ, Montori VM, Shah ND, Christianson TJH, Bryant SC, Guyatt GH, et al. The diabetes mellitus medication choice decision aid: a randomized trial. Arch Intern Med 2009 Sep 28;169(17):1560-1568. [doi: 10.1001/archinternmed.2009.293] [Medline: 19786674]

5. Rost KM, Flavin KS, Cole K, McGill JB. Change in metabolic control and functional status after hospitalization. Impact of patient activation intervention in diabetic patients. Diabetes Care 1991 Oct;14(10):881-889. [doi: 10.2337/diacare.14.10.881] [Medline: 1773686]

6. Kashaf MS, McGill ET, Berger ZD. Shared decision-making and outcomes in type 2 diabetes: a systematic review and meta-analysis. Patient Educ Couns 2017 Dec;100(12):2159-2171. [doi: 10.1016/j.pec.2017.06.030] [Medline: 28693922]

7. O'Connor AM. Validation of a decisional conflict scale. Med Decis Making 1995;15(1):25-30. [doi: 10.1177/0272989X9501500105] [Medline: 7898294] 
8. Becerra-Perez M, Menear M, Turcotte S, Labrecque M, Légaré F. More primary care patients regret health decisions if they experienced decisional conflict in the consultation: a secondary analysis of a multicenter descriptive study. BMC Fam Pract 2016 Nov 10;17(1):156 [FREE Full text] [doi: 10.1186/s12875-016-0558-0] [Medline: 27832752]

9. Kaplan AL, Crespi CM, Saucedo JD, Connor SE, Litwin MS, Saigal CS. Decisional conflict in economically disadvantaged men with newly diagnosed prostate cancer: baseline results from a shared decision-making trial. Cancer 2014 Sep 1;120(17):2721-2727 [FREE Full text] [doi: 10.1002/cncr.28755] [Medline: 24816472]

10. Solli O, Stavem K, Kristiansen IS. Health-related quality of life in diabetes: the associations of complications with EQ-5D scores. Health Qual Life Outcomes 2010 Feb 4;8:18 [FREE Full text] [doi: 10.1186/1477-7525-8-18] [Medline: 20132542]

11. Wong EM, Afshar R, Qian H, Zhang M, Elliott TG, Tang TS. Diabetes distress, depression and glycemic control in a Canadian-based specialty care setting. Can J Diabetes 2017 Aug;41(4):362-365. [doi: 10.1016/j.jcjd.2016.11.006] [Medline: 28462795]

12. Liu L, Li Y, Sha K, Wang Y, He X. Patient assessment of chronic illness care, glycemic control and the utilization of community health care among the patients with type 2 diabetes in Shanghai, China. PLoS One 2013;8(9):e73010 [FREE Full text] [doi: 10.1371/journal.pone.0073010] [Medline: 24039847]

13. Shim YT, Lee J, Toh MP, Tang WE, Ko Y. Health-related quality of life and glycaemic control in patients with type 2 diabetes mellitus in Singapore. Diabet Med 2012 Aug;29(8):e241-e248. [doi: 10.1111/j.1464-5491.2012.03689.x] [Medline: 22507291]

14. Fisher L, Polonsky WH, Hessler DM, Masharani U, Blumer I, Peters AL, et al. Understanding the sources of diabetes distress in adults with type 1 diabetes. J Diabetes Complications 2015;29(4):572-577 [FREE Full text] [doi: 10.1016/j.jdiacomp.2015.01.012] [Medline: 25765489]

15. Légaré F, Stacey D, Turcotte S, Cossi M, Kryworuchko J, Graham ID, et al. Interventions for improving the adoption of shared decision making by healthcare professionals. Cochrane Database Syst Rev 2014 Sep 15(9):CD006732. [doi: 10.1002/14651858.CD006732.pub3] [Medline: 25222632]

16. Kim J, Whitney A, Hayter S, Lewis C, Campbell M, Sutherland L, et al. Development and initial testing of a computer-based patient decision aid to promote colorectal cancer screening for primary care practice. BMC Med Inform Decis Mak 2005 Nov 28;5:36 [FREE Full text] [doi: 10.1186/1472-6947-5-36] [Medline: 16313676]

17. Bailey RA, Pfeifer M, Shillington AC, Harshaw Q, Funnell MM, VanWingen J, et al. Effect of a patient decision aid (PDA) for type 2 diabetes on knowledge, decisional self-efficacy, and decisional conflict. BMC Health Serv Res 2016 Jan 14;16:10 [FREE Full text] [doi: 10.1186/s12913-016-1262-4] [Medline: 26762150]

18. Denig P, Schuling J, Haaijer-Ruskamp F, Voorham J. Effects of a patient oriented decision aid for prioritising treatment goals in diabetes: pragmatic randomised controlled trial. Br Med J 2014 Sep 25;349:g5651 [FREE Full text] [doi: 10.1136/bmj.g5651] [Medline: 25255799]

19. Yu CH, Stacey D, Sale J, Hall S, Kaplan DM, Ivers N, et al. Designing and evaluating an interprofessional shared decision-making and goal-setting decision aid for patients with diabetes in clinical care--systematic decision aid development and study protocol. Implement Sci 2014 Jan 22;9:16 [FREE Full text] [doi: 10.1186/1748-5908-9-16] [Medline: 24450385]

20. Yu CH, Ke C, Jovicic A, Hall S, Straus SE, IP-SDM Team. Beyond pros and cons - developing a patient decision aid to cultivate dialog to build relationships: insights from a qualitative study and decision aid development. BMC Med Inform Decis Mak 2019 Sep 18;19(1):186 [FREE Full text] [doi: 10.1186/s12911-019-0898-5] [Medline: $\underline{31533828]}$

21. Eysenbach G. CONSORT-EHEALTH: implementation of a checklist for authors and editors to improve reporting of web-based and mobile randomized controlled trials. Stud Health Technol Inform 2013;192:657-661. [Medline: 23920638]

22. Campbell MK, Piaggio G, Elbourne DR, Altman DG, CONSORT Group. Consort 2010 statement: extension to cluster randomised trials. Br Med J 2012 Sep 4;345:e5661. [doi: 10.1136/bmj.e5661] [Medline: 22951546]

23. Yu CH, Ivers NM, Stacey D, Rezmovitz J, Telner D, Thorpe K, et al. Impact of an interprofessional shared decision-making and goal-setting decision aid for patients with diabetes on decisional conflict--study protocol for a randomized controlled trial. Trials 2015 Jun 27;16:286 [FREE Full text] [doi: 10.1186/s13063-015-0797-8] [Medline: 26116444]

24. Cheng AY, Barnes T. Executive summary: Canadian diabetes association 2013 clinical practice guidelines for the prevention and management of diabetes in Canada. Can J Diabetes 2013;37(Suppl 3):S291-S360 [FREE Full text]

25. Staying Healthy With Diabetes. Diabetes Canada |Clinical Practice Guidelines. 2012. URL: https://guidelines.diabetes.ca/ docs/patient-resources/staying-healthy-with-diabetes.pdf [accessed 2020-09-14]

26. User Manual - Decision Conflict Scale. Patient Decision Aids - Ottawa Hospital Research Institute. 1993. URL: http:/ /decisionaid.ohri.ca/docs/develop/User Manuals/UM Decisional Conflict.pdf [accessed 2020-09-04]

27. Polonsky WH, Fisher L, Earles J, Dudl RJ, Lees J, Mullan J, et al. Assessing psychosocial distress in diabetes: development of the diabetes distress scale. Diabetes Care 2005 Mar;28(3):626-631. [doi: 10.2337/diacare.28.3.626] [Medline: 15735199]

28. Ware J. SF-36 Physical \& Mental Health Summary Scales: A Manual for Users of Version 1. Boston, MA: Health Assessment Lab; 1994.

29. Glasgow RE, Whitesides H, Nelson CC, King DK. Use of the patient assessment of chronic illness care (PACIC) with diabetic patients: relationship to patient characteristics, receipt of care, and self-management. Diabetes Care 2005 Nov;28(11):2655-2661. [doi: 10.2337/diacare.28.11.2655] [Medline: 16249535] 
30. Francis J, Eccles M, Johnston M, Walker A, Grimshaw J, Foy R, et al. Constructing Questionnaires Based on the Theory of Planned Behavior? A Manual for Health Services Researchers. Newcastle upon Tyne, UK: Centre for Health Services Research; 2004.

31. Ware J, Kosinski M, Keller SD. A 12-item short-form health survey: construction of scales and preliminary tests of reliability and validity. Med Care 1996 Mar;34(3):220-233. [doi: 10.1097/00005650-199603000-00003] [Medline: $\underline{\text { 8628042] }}$

32. Bohannon RW, Maljanian R, Landes M. Test-retest reliability of short form (SF)-12 component scores of patients with stroke. Int J Rehabil Res 2004 Jun;27(2):149-150. [doi: 10.1097/01.mrr.0000127350.25287.08] [Medline: 15167113]

33. Cheak-Zamora NC, Wyrwich KW, McBride TD. Reliability and validity of the SF-12v2 in the medical expenditure panel survey. Qual Life Res 2009 Aug;18(6):727-735. [doi: 10.1007/s11136-009-9483-1] [Medline: 19424821]

34. Schmittdiel J, Mosen DM, Glasgow RE, Hibbard J, Remmers C, Bellows J. Patient assessment of chronic illness care (PACIC) and improved patient-centered outcomes for chronic conditions. J Gen Intern Med 2008 Jan;23(1):77-80 [FREE Full text] [doi: 10.1007/s11606-007-0452-5] [Medline: 18030539$]$

35. Szecsenyi J, Rosemann T, Joos S, Peters-Klimm F, Miksch A. German diabetes disease management programs are appropriate for restructuring care according to the chronic care model: an evaluation with the patient assessment of chronic illness care instrument. Diabetes Care 2008 Jun;31(6):1150-1154. [doi: 10.2337/dc07-2104] [Medline: 18299443]

36. Légaré F, Borduas F, Freitas A, Jacques A, Godin G, Luconi F, CPD-KT team. Development of a simple 12-item theory-based instrument to assess the impact of continuing professional development on clinical behavioral intentions. PLoS One 2014;9(3):e91013 [FREE Full text] [doi: 10.1371/journal.pone.0091013] [Medline: 24643173]

37. Légaré F, Guerrier M, Nadeau C, Rhéaume C, Turcotte S, Labrecque M. Impact of DECISION +2 on patient and physician assessment of shared decision making implementation in the context of antibiotics use for acute respiratory infections. Implement Sci 2013 Dec 26;8:144 [FREE Full text] [doi: 10.1186/1748-5908-8-144] [Medline: 24369771]

38. Heneghan C, Perera R, Ward A, Fitzmaurice D, Meats E, Glasziou P. Assessing differential attrition in clinical trials: self-monitoring of oral anticoagulation and type II diabetes. BMC Med Res Methodol 2007 May 2;7:18 [FREE Full text] [doi: 10.1186/1471-2288-7-18] [Medline: 17474976]

39. Légaré F, O'Connor AM, Graham ID, Wells GA, Tremblay S. Impact of the Ottawa decision support framework on the agreement and the difference between patients' and physicians' decisional conflict. Med Decis Making 2006;26(4):373-390. [doi: 10.1177/0272989X06290492] [Medline: 16855126]

40. Jakobsen JC, Gluud C, Wetterslev J, Winkel P. When and how should multiple imputation be used for handling missing data in randomised clinical trials - a practical guide with flowcharts. BMC Med Res Methodol 2017 Dec 6;17(1):162 [FREE Full text] [doi: 10.1186/s12874-017-0442-1] [Medline: 29207961]

41. Twisk J, de Boer M, de Vente W, Heymans M. Multiple imputation of missing values was not necessary before performing a longitudinal mixed-model analysis. J Clin Epidemiol 2013 Sep;66(9):1022-1028. [doi: 10.1016/j.jclinepi.2013.03.017] [Medline: 23790725]

42. Collins LM, Schafer JL, Kam CM. A comparison of inclusive and restrictive strategies in modern missing data procedures. Psychol Methods 2001 Dec;6(4):330-351. [Medline: 11778676]

43. Kuznetsova A, Brockhoff PB, Christensen RH. Package: tests in linear mixed effects models. J Stat Soft 2017;82(13):-. [doi: $10.18637 /$ jss.v082.i13]

44. The R Project for Statistical Computing. 2018. URL: https://www.R-project.org/ [accessed 2019-05-03]

45. Stacey D, Légaré F, Lewis K, Barry MJ, Bennett CL, Eden KB, et al. Decision aids for people facing health treatment or screening decisions. Cochrane Database Syst Rev 2017 Apr 12;4:CD001431 [FREE Full text] [doi: 10.1002/14651858.CD001431.pub5] [Medline: 28402085]

46. Rutherford C, King MT, Butow P, Legare F, Lyddiatt A, Souli I, et al. Is quality of life a suitable measure of patient decision aid effectiveness? Sub-analysis of a Cochrane systematic review. Qual Life Res 2019 Mar;28(3):593-607. [doi: 10.1007/s11136-018-2045-7] [Medline: 30426276]

47. van Weert JC, van Munster BC, Sanders R, Spijker R, Hooft L, Jansen J. Decision aids to help older people make health decisions: a systematic review and meta-analysis. BMC Med Inform Decis Mak 2016 Apr 21;16:45 [FREE Full text] [doi: 10.1186/s12911-016-0281-8] [Medline: 27098100]

48. Hall AK, Bernhardt JM, Dodd V, Vollrath MW. The digital health divide: evaluating online health information access and use among older adults. Health Educ Behav 2015 Apr;42(2):202-209 [FREE Full text] [doi: 10.1177/1090198114547815] [Medline: 25156311]

49. Loudon K, Treweek S, Sullivan F, Donnan P, Thorpe KE, Zwarenstein M. The PRECIS-2 tool: designing trials that are fit for purpose. Br Med J 2015 May 8;350:h2147. [doi: 10.1136/bmj.h2147] [Medline: 25956159]

50. Horevoorts NJ, Vissers PA, Mols F, Thong MS, van de Poll-Franse LV. Response rates for patient-reported outcomes using web-based versus paper questionnaires: comparison of two invitational methods in older colorectal cancer patients. J Med Internet Res 2015 May 7;17(5):e111 [FREE Full text] [doi: 10.2196/jmir.3741] [Medline: 25953059]

51. Ebert JF, Huibers L, Christensen B, Christensen MB. Paper- or web-based questionnaire invitations as a method for data collection: cross-sectional comparative study of differences in response rate, completeness of data, and financial cost. J Med Internet Res 2018 Jan 23;20(1):e24 [FREE Full text] [doi: 10.2196/jmir.8353] [Medline: 29362206] 
52. Knechel NA. The challenges of enrolling older adults into intervention studies. Yale J Biol Med 2013 Mar;86(1):41-47 [FREE Full text] [Medline: 23482244]

53. Rahimi K, Malhotra A, Banning AP, Jenkinson C. Outcome selection and role of patient reported outcomes in contemporary cardiovascular trials: systematic review. Br Med J 2010 Nov 1;341:c5707 [FREE Full text] [doi: 10.1136/bmj.c5707] [Medline: 21041324]

54. Costlow MR, Landsittel DP, James AE, Kahn JM, Morton SC. Model for a patient-centered comparative effectiveness research center. Clin Transl Sci 2015 Apr;8(2):155-159 [FREE Full text] [doi: 10.1111/cts.12257] [Medline: 25588873]

55. Stolee P, Rockwood K, Fox RA, Streiner DL. The use of goal attainment scaling in a geriatric care setting. J Am Geriatr Soc 1992 Jun;40(6):574-578. [doi: 10.1111/j.1532-5415.1992.tb02105.x] [Medline: 1587973]

56. Freemantle N, Calvert M, Wood J, Eastaugh J, Griffin C. Composite outcomes in randomized trials: greater precision but with greater uncertainty? J Am Med Assoc 2003 May 21;289(19):2554-2559. [doi: 10.1001/jama.289.19.2554] [Medline: $\underline{12759327]}$

\author{
Abbreviations \\ CIHR: Canadian Institutes of Health Research \\ CONSORT: Consolidated Standards of Reporting Trials \\ DCS: Decisional Conflict Scale \\ EMR: electronic medical record \\ FHT: Family Health Team \\ IPSDM: interprofessional shared decision-making \\ PtDA: patient decision aid \\ RCT: randomized controlled trial \\ SDM: shared decision making
}

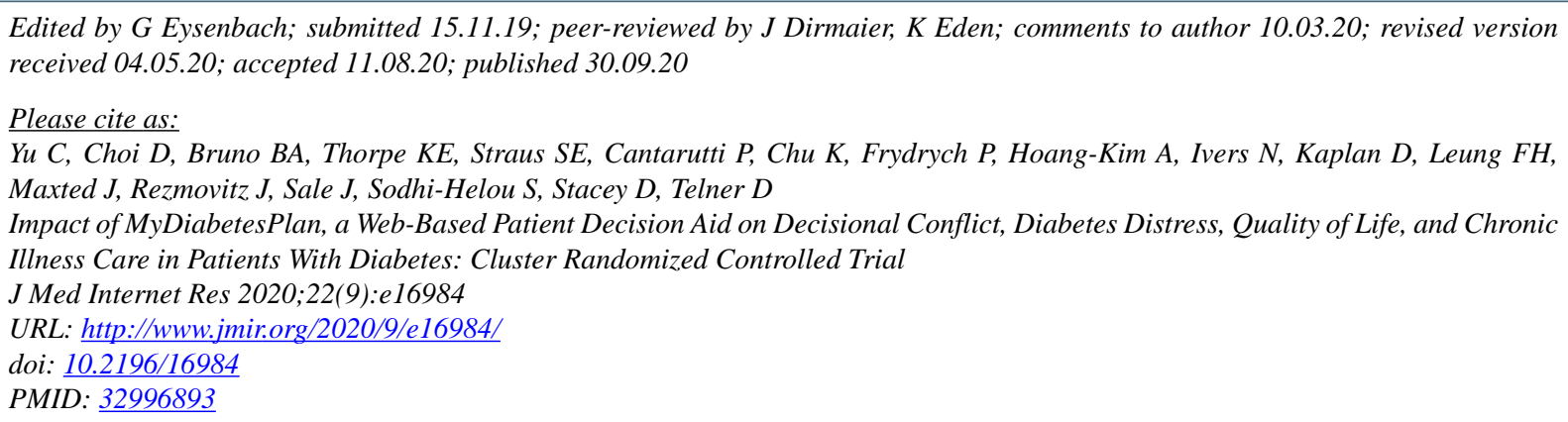

(C) Catherine Yu, Dorothy Choi, Brigida A Bruno, Kevin E Thorpe, Sharon E Straus, Paul Cantarutti, Karen Chu, Paul Frydrych, Amy Hoang-Kim, Noah Ivers, David Kaplan, Fok-Han Leung, John Maxted, Jeremy Rezmovitz, Joanna Sale, Sumeet Sodhi-Helou, Dawn Stacey, Deanna Telner. Originally published in the Journal of Medical Internet Research (http://www.jmir.org), 30.09.2020. This is an open-access article distributed under the terms of the Creative Commons Attribution License (https://creativecommons.org/licenses/by/4.0/), which permits unrestricted use, distribution, and reproduction in any medium, provided the original work, first published in the Journal of Medical Internet Research, is properly cited. The complete bibliographic information, a link to the original publication on http://www.jmir.org/, as well as this copyright and license information must be included. 